\title{
Layer 4 Pyramidal Neurons Exhibit Robust Dendritic Spine Plasticity In Vivo after Input Deprivation
}

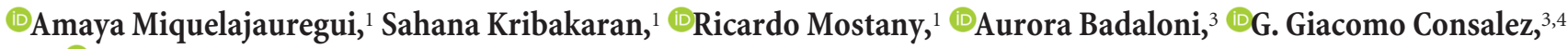 \\ and Carlos Portera-Cailliau ${ }^{1,2}$ \\ Departments of ${ }^{1}$ Neurology and ${ }^{2}$ Neurobiology, David Geffen School of Medicine at UCLA, Los Angeles, California 90095, ${ }^{3}$ Division of Neuroscience, San \\ Raffaele Scientific Institute, 20132 Milan, Italy, and ${ }^{4}$ Università Vita-Salute San Raffaele, 20132 Milan, Italy
}

Pyramidal neurons in layers $2 / 3$ and 5 of primary somatosensory cortex (S1) exhibit somewhat modest synaptic plasticity after whisker input deprivation. Whether neurons involved at earlier steps of sensory processing show more or less plasticity has not yet been examined. Here, we used longitudinal in vivo two-photon microscopy to investigate dendritic spine dynamics in apical tufts of GFP-expressing layer 4 (L4) pyramidal neurons of the vibrissal (barrel) S1 after unilateral whisker trimming. First, we characterize the molecular, anatomical, and electrophysiological properties of identified L4 neurons in Ebf2-Cre transgenic mice. Next, we show that input deprivation results in a substantial ( $\sim 50 \%)$ increase in the rate of dendritic spine loss, acutely (4-8 $\mathrm{d})$ after whisker trimming. This robust synaptic plasticity in L4 suggests that primary thalamic recipient pyramidal neurons in $\mathrm{S} 1 \mathrm{may}$ be particularly sensitive to changes in sensory experience. Ebf2-Cre mice thus provide a useful tool for future assessment of initial steps of sensory processing in S1.

Key words: optogenetics; barrel cortex; two-photon; electrophysiology; Ebf2; whisker

\section{Introduction}

As recipients of most synaptic inputs in the neocortex, dendritic spines are central to neuronal function. Using time-lapse in vivo two-photon microscopy of fluorescently labeled neurons, it has been possible to study dynamic aspects of synapse formation and elimination (Holtmaat and Svoboda, 2009), which correlate with synaptic adaptations taking place during normal brain development (Holtmaat et al., 2005; Zuo et al., 2005a; Cruz-Martín et al., 2010), in response to changes in sensory experience (Holtmaat and Svoboda, 2009) or as a result of learning (Xu et al., 2009; Yang et al., 2014). The importance of spine dynamics has been exem-

\section{Received Dec. 19, 2014; revised March 17, 2015; accepted April 6, 2015}

Author contributions: A.M. and C.P.-C. designed research; A.M., S.K., R.M., A.B., and C.P.-C. performed research; A.B. and G.G.C. contributed unpublished reagents/analytic tools; A.M., S.K., and C.P.-C. analyzed data; A.M., R.M., G.G.C., and C.P.-C. wrote the paper.

This study was supported by UCLA's CTSI Grant Number UL1TR000124 (NIH/NCATS), by Grants 1R01MH083785 and 1R21MH100614 from the National Institute for Mental Health (C.P.-C.), a NARSAD Young Investigator Grant from the Brain and Behavior Research Foundation (A.M.), an Undergraduate Research Fellowship Program funded by The Milton Gottlieb Scholarship (S.K.), and the Italian Telethon Foundation (G.G.C.). We thank Drs Carlos Cepeda and Joyce Wondolowsky for helpful discussions regarding the electrophysiology, Dr Karel Svoboda and Tim O'Connor for the spine analysis software, Dr Daniel Fiole for assistance with MATLAB, Dr Bennett Novitch, Dr Caroline Pearson, Dr Barbara Rust, and Aaron Lulla for assistance with immunohistochemistry, Drs Matthew Shtrahman and Raul Serrano for help with optogenetics hardware, and Sitaram Vangala, Tristan Grogan (UCLA-CTSI), Jeffrey Gornbein (UCLA-Biomathematics), and Dr. Anubhuthi Goel for help with statistics.

The authors declare no competing financial interests.

Correspondence should be addressed to either Dr Amaya Miquelajauregui or Dr Carlos Portera-Cailliau, Departments of Neurology and Neurobiology, David Geffen School of Medicine at UCLA, Reed Neurological Research Center, Room A-145, 710 Westwood Plaza, Los Angeles, CA 90095. E-mail: amaya.miq@gmail.com or cpcailliau@mednet.ucla.edu.

R. Mostany's present address: Department of Pharmacology, Tulane University School of Medicine, New Orleans, LA.

DOI:10.1523/JNEUROSCI.5215-14.2015

Copyright $\odot 2015$ the authors $\quad 0270-6474 / 15 / 357287-08 \$ 15.00 / 0$ plified in the context of experience-dependent plasticity in the vibrissal primary somatosensory cortex (S1), where sensory input deprivation can alter the rate of spine turnover of layer (L) $5 \mathrm{~B}$ pyramidal neurons or the likelihood that they are stabilized (Zuo et al., 2005b; Holtmaat et al., 2006; Wilbrecht et al., 2010; Schubert et al., 2013).

The cortical representation of the rodent vibrissae is somatotopically organized into discrete columnar units in S1 known as "barrels" (Feldmeyer et al., 2013). Complete whisker trimming in adult mice leads to reduced spine elimination 1 month later, but not in the first 2 weeks after trimming (Zuo et al., 2005b). In contrast, "chessboard" trimming (which promotes competition between neighboring barrels) results in a greater probability of stabilization of new persistent $(>8 \mathrm{~d}$ ) spines in L5B neurons at the border between spared and deprived barrels (Holtmaat et al., 2006; Wilbrecht et al., 2010). Intriguingly, the more drastic paradigm of whisker follicle ablation does not change either the density or the dynamics of spines from L5B neurons, but leads to an increase in the density of new spines of L2/3 pyramidal neurons (Schubert et al., 2013).

A limitation of these studies has been the focus on L5B (occasionally L2/3) pyramidal neurons because those are the cells labeled in Thyl GFP-M and YFP-H mice (Feng et al., 2000). In contrast, spines of L4 neurons, which are the primary recipients of thalamic sensory inputs, have not yet been studied in vivo. Here, we tested the hypothesis that L4 pyramidal neuron spines exhibit experience-dependent plasticity, because of the privileged role of L4 in the cortical sensory processing hierarchy (Feldmeyer et al., 2013), albeit direct inputs from thalamus to L5 neurons have also been described by Constantinople and Bruno (2013). Therefore, we examined the effect of input deprivation on apical 
dendritic spines of L4 pyramidal neurons (readily accessible for in vivo imaging), which are thought to both receive direct thalamic sensory information and integrate information from multiple inputs (Staiger et al., 2004; Schoonover et al., 2014). Using longitudinal two-photon microscopy in the barrel cortex of Ebf2-Cre mice, we find that sensory deprivation by contralateral whisker trimming leads to a rapid loss of spines (within 4-8 d) in L4 pyramids.

\section{Materials and Methods}

Animals and $r A A V$ constructs. We used Ebf2Cre BAC-transgenic mice (MGI:4421668) of either sex expressing Cre recombinase under the Ebf2 promoter and genotyped for Cre (Chiara et al., 2012). All the procedures described in this study were approved by the University of California Chancellor's Animal Research Committee and the UCLA EH\&S Biosafety Division. rAAVs were purchased from the University of Pennsylvania Vector Core: rAAV2/1.CAG.FLEX.EGFP.WPRE.bGH ("rAAV-EGFP"; Allen Institute 854) and rAAV2/ 1.EF1a.DIO.hChR2(H134R)-EYFP.WPRE.hGH ("rAAV-ChR2"; Addgene 20298).

Whisker trimming. Unilateral trimming of the contralateral vibrissae was performed every $1-2 \mathrm{~d}$ for $16 \mathrm{~d}$ using a whisker pocket trimmer (Wahl) without anesthesia.

In utero $r A A V$ injections. In utero injections were described previously (Cruz-Martín et al., 2010). Approximately $0.3 \mu \mathrm{l}$ of rAAV-solution (titer $=\mathrm{e}^{12}-\mathrm{e}^{13}$ with $0.1 \%$ Fast Green) was pressure-injected into the right lateral cerebral ventricle at E15.

Histology. Mouse perfusion and tissue preparation was performed as described previously (Chiara et al., 2012). Briefly, sections (30-40 $\mu \mathrm{m})$ were blocked in PBS containing 5\% Goat serum (Thermo Fisher Scientific PCN5000) and $0.1 \%$ Triton X-100 (SigmaAldrich), and then incubated with primary antibodies overnight at RT at the following dilutions: chicken anti-GFP (1:500, Millipore Bioscience Research Reagents AB16901), guinea pig anti-VGlut2 (1:2000, Millipore Bioscience Research Reagents, AB2251), rabbit anti-Cux1 (1:500, Santa-Cruz Biotechnology, sc-13024), rat anti-Ctip2 (1:750, Abcam AB18465), and rabbit anti-GABA (1:500, Sigma-Aldrich A2052). For secondary antibodies, we used donkey anti-chicken-FITC (Jackson Laboratories), AlexaFluor 568 donkey anti-rabbit, AlexaFluor 568 goat anti-guinea pig, and Cy5-goat anti-rat (all from Life Technologies). Vectashield (Vector Laboratories) was used for mounting.

Morphological analysis and cell quantification. Neuron reconstruction and morphological analysis was performed in Neurolucida (MicroBrightField; $n=48 / 11$ neurons/mice). For unbiased cluster analysis, we used $k$ means in MATLAB using three parameters: maximum branch order, total length of apical dendrite, and depth at first bifurcation. Cell density quantifications (Fig. 1) were done in ImageJ

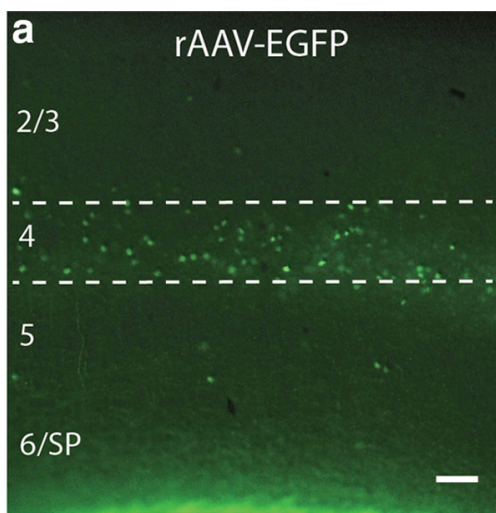

b
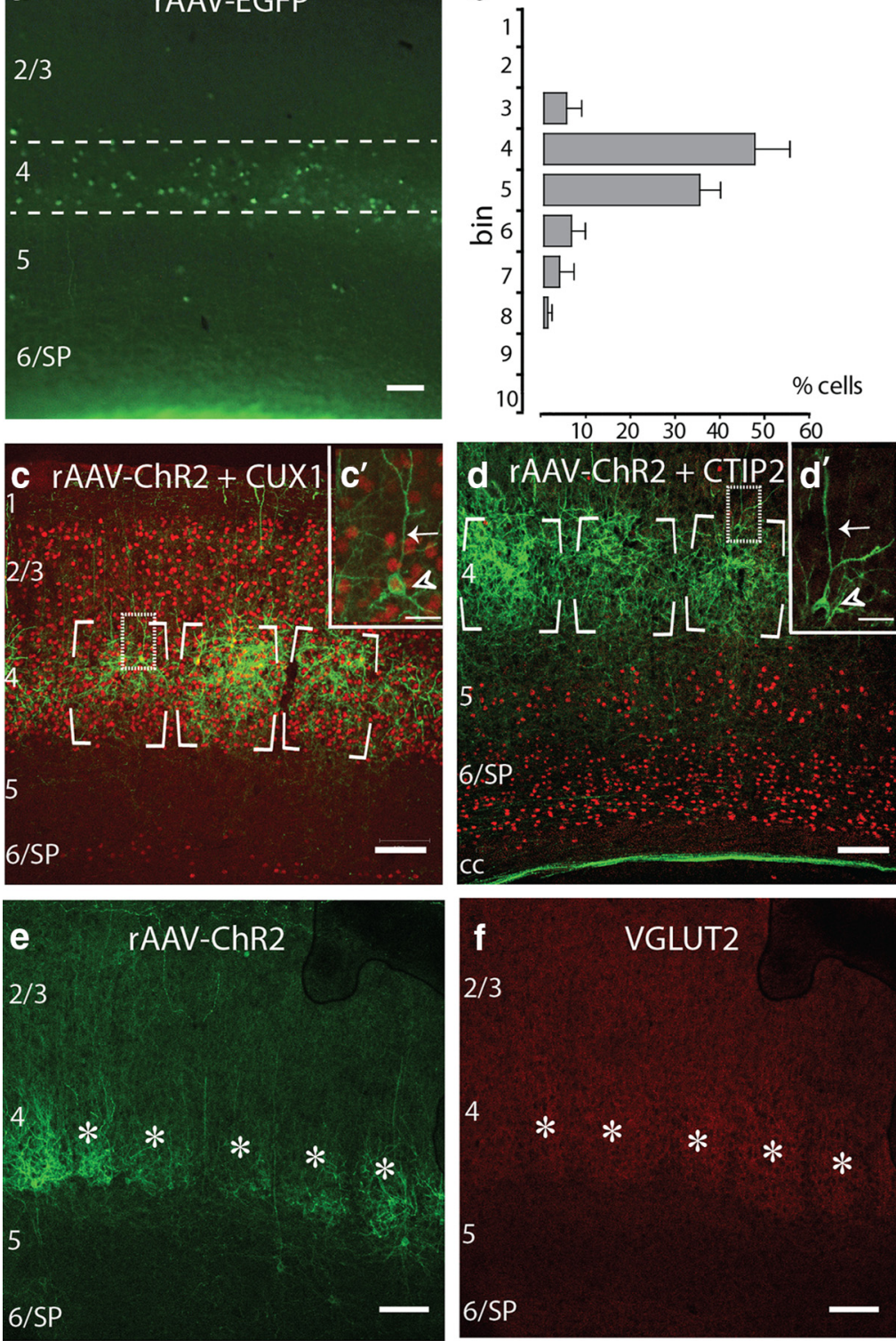

g

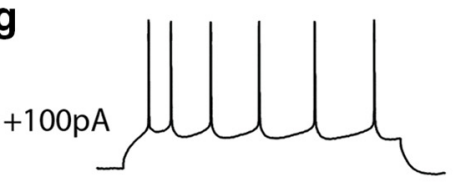

h
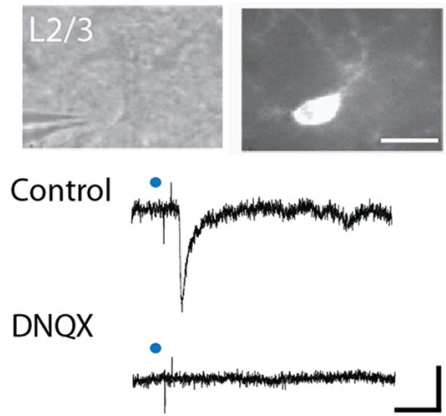

Figure 1. Ebf2 labels $L 4$ neurons in somatosensory cortex. $\boldsymbol{a}$, Coronal section through $\mathrm{S} 1$ of an adult Ebf2-Cremouse injected at E15 with rAAV-EGFP. $\boldsymbol{b}$, Cell quantification of Ebf2 + cells across cortical layers. Dashed lines in $\boldsymbol{a}$ delineate $L 4$ (bins $4-5$ ). Approximately $84 \%$ of Ebf2 + cells in the neocortex of Ebf2-Cre;rAAV-EGFP mice were in L4. $\boldsymbol{c}, \boldsymbol{d}$, Adult coronal Ebf2-Cre;rAAV-ChR2 sections immunostained against Cux1 (c) and Ctip2 (d; both red) to label boundaries of L2-4 and L5-6, respectively. Insets $\left(\boldsymbol{c}^{\prime}, \boldsymbol{d}^{\prime}\right)$ are confocal sections of representative pyramidal neurons (arrowheads) with a prominent apical dendrite (arrows). $\boldsymbol{e}, \boldsymbol{f}$, Ebf2-Cre;rAAV-ChR2 expression at P11 broadly overlaps with VGlut2 + expression (red) at individual barrels (asterisks). $\boldsymbol{g}$, Representative whole-cell patch-clamp recordings in acute slices of an adult Ebf2 + p neuron in response to a depolarizing current injection (100 pA; top) and to optogenetic stimulation (3 ms, $10 \mathrm{~Hz}$; bottom). $\boldsymbol{h}$, Optogenetic stimulation of Ebf $2+L 4$ neurons ( $3 \mathrm{~ms}$, single pulse) triggers an EPSP in a L2/3 pyramidal neuron (middle) targeted under DIC optics (top left), and filled intracellularly with AlexaFluor 594 (top right). The response is completely blocked by DNQX (bottom). Scale bars: $\boldsymbol{a}-\boldsymbol{f}, 100 \mu \mathrm{m} ; \boldsymbol{c}^{\prime}, \boldsymbol{d}^{\prime}, 50 \mu \mathrm{m} ; \boldsymbol{h}$ (top), $20 \mu \mathrm{m} ; \boldsymbol{g}, \boldsymbol{h}, 20 \mathrm{mV}$ and $100 \mathrm{~ms}$. 
( $n=5$ ROIs $0.2 \times 0.8 \mathrm{~mm}, 5$ sections from 3 mice) comprising the entire cortical depth at S1; normalized values were averaged and plotted in GraphPad Prism and expressed as mean \pm SEM.

Electrophysiology and optogenetics. Acute brain slices (350 $\mu \mathrm{m}$ thick) from adult Ebf2-Cre;rAAV-ChR2 mice were obtained using vibratome (VT1000, Leica), placed on a chamber maintained at $32^{\circ}-35^{\circ} \mathrm{C}$ and submerged in ACSF containing the following (in $\mathrm{mm}$ ): $119 \mathrm{NaCl}, 2.5 \mathrm{KCl}, 1$ MgSO 4, $1.25 \mathrm{NaH}_{2} \mathrm{PO}_{4}, 2 \mathrm{CaCl} 2,26 \mathrm{NaHCO}_{3}$, and 25 glucose, perfused at a rate of $2-4 \mathrm{ml} / \mathrm{min}$, and bubbled with $95 \% \mathrm{O}_{2}$ and $5 \% \mathrm{CO}_{2}$. $\mathrm{L} 4$ and L2/3 neurons were identified using EYFP fluorescence and differential interference contrast (DIC) optics, respectively, using a $40 \times / 0.9 \mathrm{NA}$ water-immersion objective (Olympus). Glass microelectrodes (4-6 $\mathrm{M} \Omega$ ) for patch-clamp recordings were filled with internal solution containing the following (in mM): $130 \mathrm{~K}$-gluconate, $10 \mathrm{KCl}, 10 \mathrm{HEPES}, 10 \mathrm{Na}$ phosphocreatine, $4 \mathrm{Mg}$-ATP, $0.4 \mathrm{GTP}, 2 \mathrm{NaCl}$, and 0.02 AlexaFluor 594. Recordings were performed using whole-cell technique in current-clamp configuration with a patch-clamp amplifier (Multiclamp, Molecular Devices). Input resistance $\left(R_{\mathrm{in}}\right)$ was calculated at $-70 \mathrm{pA} ; \mathrm{Vm}$ and $R_{\text {in }}$ were expressed as median $\pm \mathrm{SD}$ ( $n=3$ neurons, 3 mice). For optogenetics, short pulses $(3 \mathrm{~ms})$ of blue light $(473 \mathrm{~nm})$ were delivered through the objective using a custom-made LED stimulation system.

Cranial window surgery. Chronic glass-covered cranial windows were implanted in adult mice as described previously (Mostany and PorteraCailliau, 2008; Holtmaat et al., 2009).

IOS. Intrinsic optical signal (IOS) imaging was performed to map the barrel field using contralateral stimulation of a bundle of whiskers and custom-written MATLAB routines, as described previously (Johnston et al., 2013).

High-resolution in vivo two-photon imaging of dendritic structure. Imaging was done under light isoflurane anesthesia (1-1.5\%) with a custom-built two-photon microscope, using a Ti:Sapph laser $(910 \mathrm{~nm}$, Chameleon Ultra II, Coherent), as previously described (Mostany et al., 2013), using ScanImage software (Pologruto et al., 2003). A preliminary imaging session at low-magnification was performed to identify potential candidates for dendritic imaging. High-magnification images $(512 \times$ 512 pixels, $0.152 \mu \mathrm{m} /$ pixel, $1.5 \mu \mathrm{m} z$-steps) were obtained for analysis of dendritic spines in apical tufts of L4 pyramidal neurons. For display purposes, we used "best" projections $(x y z)$ of dendritic stacks, as described previously (Mostany et al., 2013).

Spine analysis. Data on the density and dynamics of spines was obtained using the Spine Analysis program included in ScanImage software. We analyzed dendritic spines in $n=35$ dendritic segments from 29 neurons in nine mice ( $4 \mathrm{M} / 5 \mathrm{~F}$; age $=5.5 \pm 0.5$ months). Total number of spines $n=511$ over $0.95 \mathrm{~mm}$ of total dendritic length. Dynamics of spines are expressed as a fraction of the total spine number. To avoid unnecessary statistical contrasts, imaging sessions were grouped (in days) as follows: pre/basal $(-8,-4$, and 0$)$, early $(+4,+8)$, and late $(+12,+16)$ after treatment (beginning of whisker trimming), and we compared post-treatment groups with baseline. We performed a linear mixed model with a fixed treatment effect and a random effect with "dendrite" nested within "mouse," which takes into account that observations from the same mouse are correlated. Multiple comparisons were controlled using the false discovery rate at $5 \%$. Survival fraction was calculated as described previously (Mostany et al., 2013), with groups compared using one-way-ANOVA with Tukey's post hoc test (95\% confidence interval).

\section{Results}

\section{L4 excitatory neurons are labeled in Ebf2-Cre mice}

We identified expression in L4 neurons of adult S1 cortex when we injected E15 Ebf2-Cre mouse embryos (Chiara et al., 2012) with a conditional rAAV-flex-EGFP (rAAV-EGFP) construct (see Materials and Methods; Fig. 1a). A similar pattern of expression in L4 was seen when we crossed Ebf2-Cre mice to fluorescent reporter R26-stop-EYFP mice to generate Ebf2-Cre;R26R-YFP offspring (data not shown), though isolated expression was also found in infragranular layers (especially L6), in the subplate (SP), and in surviving Cajal-Retzius neurons (Chiara et al., 2012).
Compared with Ebf2-Cre;R26R-YFP, rAAV-EGFP injections in Ebf2-Cre mice produced minimal expression in L6/SP, presumably due to selective rAAV tropism (Fig. $1 a, b$ ). We found that the enrichment of Ebf2-Cre expression (referred to as Ebf2+) in L4 begins early in postnatal cortical development [postnatal day (P)10-P11] and does not colocalize with GABA (data not shown).

We further identified Ebf2 + cells as excitatory neurons of L4 with additional experiments. First, we injected Ebf2-Cre embryos at E15 with a conditional rAAV-DIO-ChR2-EYFP (rAAV-ChR2) vector, which revealed barrel-like clusters of expression in S1. Of note, although the vast majority of Ebf $2+$ neurons exhibited a morphology typical of L4 spiny stellate neurons, a subset of $\mathrm{Ebf} 2+$ neurons were identified as L4 pyramidal $(\mathrm{Ebf} 2+\mathrm{p})$ neurons, as evidenced by the presence of an apical dendrite extending toward the pial surface (Fig. $1 c^{\prime}, d^{\prime}$ ). Second, immunostaining against Cux1 and Ctip2 (Fig. $1 c, d$ ), markers of excitatory neurons of L2-4 and L5-6, respectively (Li et al., 2013; Pouchelon et al., 2014) showed that Ebf2 expression completely overlapped with the lower border of Cuxl expression (Fig. $1 c, c^{\prime}$ ) but was excluded from the territory of Ctip2 expression (Fig. 1d). Importantly, Ebf $2+$ p neurons clearly expressed Cux1 at the soma but were devoid of Ctip2 expression (Fig. $1 c^{\prime}, d^{\prime}$ ). Third, Vglut2 labeling of thalamocortical axons at P11 (Li et al., 2013; Fig. 1e,f) and cytochrome oxidase staining of adult mice (data not shown) both showed that the vast majority of Ebf2 + neurons reside within barrels.

We next performed whole-cell patch-clamp recordings of visually identified $\mathrm{Ebf} 2+\mathrm{p}$ neurons in acute brain slices from Ebf2Cre;rAAV-EGFP mice. Ebf $2+\mathrm{p}$ neurons in $\mathrm{L} 4$ had a resting membrane potential $\left(V_{\mathrm{m}}\right)$ of $65 \pm 3.7 \mathrm{mV}$ and input resistance $\left(R_{\mathrm{in}}\right)$ of $144.3 \pm 16.5$. A depolarizing current injection pulse of $100 \mathrm{pA}$ triggered a train of action potentials and spike adaptation characteristic of regular spiking pyramidal neurons (Fig. 1g). Optogenetic stimulation of Ebf2-Cre;rAAV-ChR2 expressing L4 neurons (including pyramidal cells), generated reliable action potential responses to brief ( $3 \mathrm{~ms}$ ) pulses of blue light at rates of $10 \mathrm{~Hz}$ (Fig. $1 \mathrm{~g}$ ). Optogenetic stimulation of Ebf $2+$ neurons was sufficient to synaptically trigger EPSP responses in individually recorded L2/3 pyramidal neurons in a DNQX-dependent manner (Fig. $1 h)$.

\section{Anatomical features of Ebf $2+\mathrm{L} 4$ pyramidal neurons based on the morphology of their apical dendritic tufts}

Although excitatory neurons of the mouse somatosensory L4 are mainly represented by spiny stellate neurons, pyramidal and star pyramidal neurons have also been described (Lübke et al., 2000; Staiger et al., 2004; Schoonover et al., 2014). The sparse labeling of Ebf $2+$ p obtained with our approach allowed us to perform in vivo two-photon imaging of their apical dendritic tufts through a cranial window implanted over barrel cortex. We used Neurolucida to trace dendritic arbors in the image stacks and analyzed the morphological characteristics of $48 \mathrm{Ebf} 2+\mathrm{p}$ neurons (Fig. $2 a-d$; see Materials and Methods). In 19 of these neurons (40\%) we successfully traced the primary apical dendrite all the way back to its cell body at an average depth of $399.8 \pm 15.5 \mu \mathrm{m}$ (which is similar to the average depth of spiny stellate neurons; $377.7 \pm$ $11.9 \mu \mathrm{m}, n=54)$, corresponding to the expected depth for L4 in adult mice (310-520 $\mu \mathrm{m}$ below the pia (Jia et al., 2014)). The average total length of the entire dendritic tuft (measured from the first branching point of the main apical branch) was $730.6 \pm$ $84.0 \mu \mathrm{m}$; the average depth below the pial surface of the first branching point was $92.0 \pm 7.4 \mu \mathrm{m}$; the average number of 
a

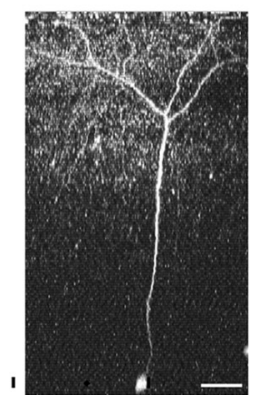

C

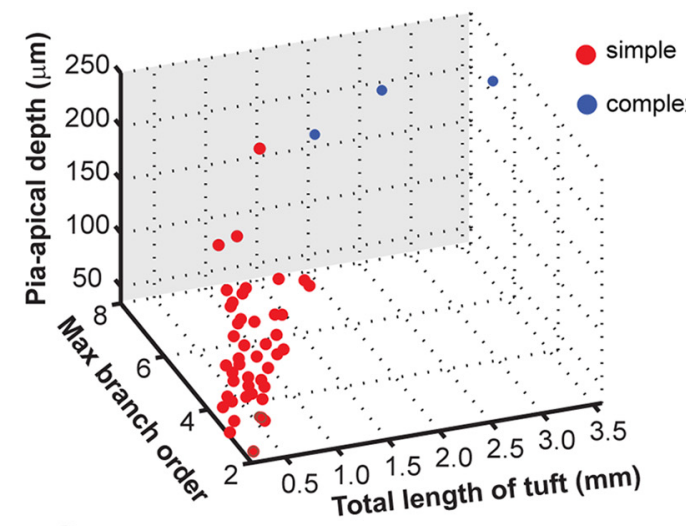

e $\stackrel{-}{\check{I}}$

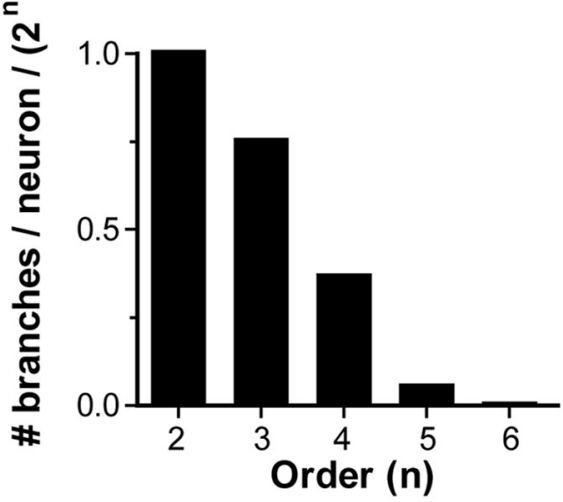

g

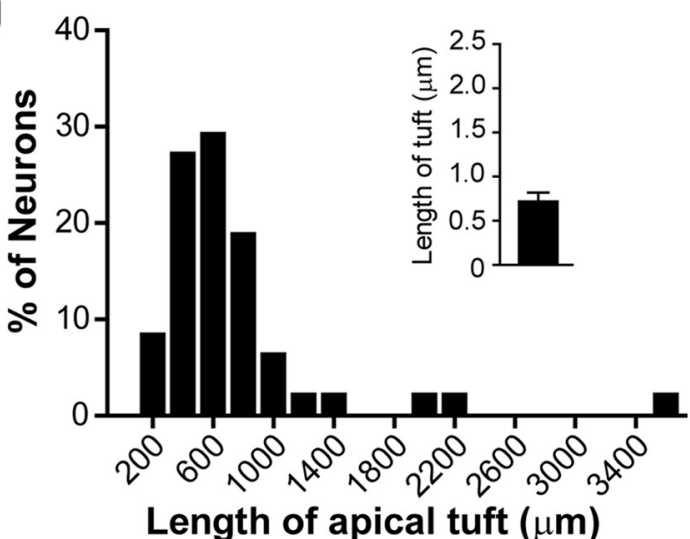

b

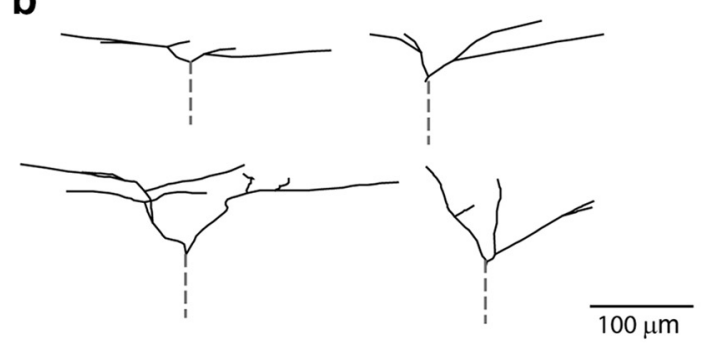

d Representative (simple) L4p neuron

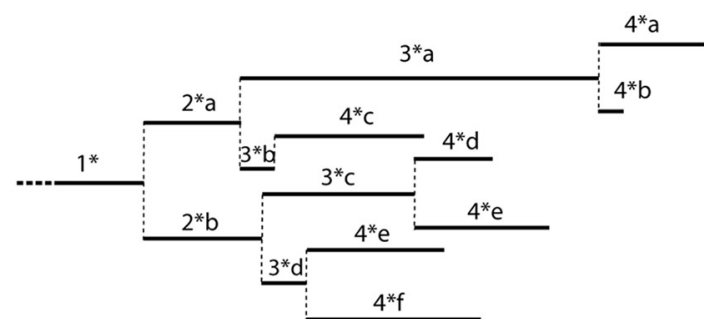

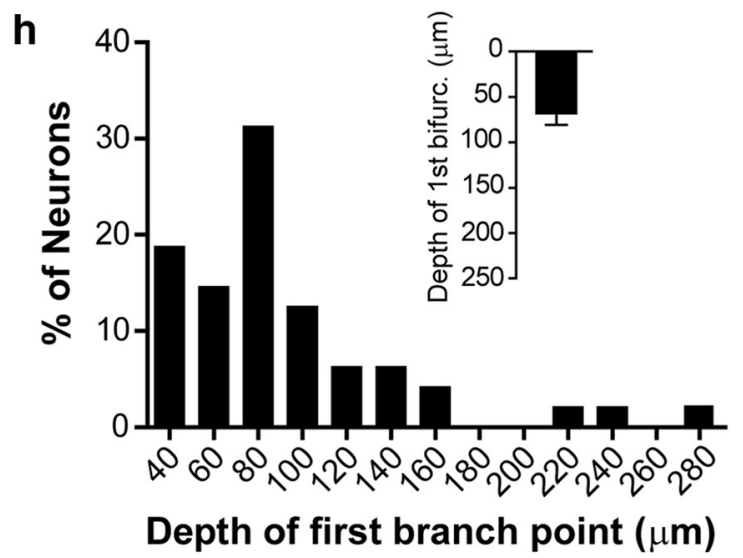

Figure 2. Morphology of Ebf2 + pyramidal neurons in L4 (apical tufts). $\boldsymbol{a}$, Two-photon image of a representative Ebf2 $+\mathrm{L} 4$ pyramidal neuron (soma depth $\sim 453 \mu \mathrm{m}$ ) and a dendritic segment in L1 (max proj, 17 slices, $2 \mu \mathrm{m}$ apart) acquired in vivo in an adult Ebf2-Cre;rAAV-EGFP mouse. Scale bars: $\boldsymbol{a}, 50 \mu \mathrm{m} ; \boldsymbol{b}, 100 \mu \mathrm{m}$. $\boldsymbol{b}$, Neurolucida reconstructions of apical dendritic tufts from four representative neurons imaged in vivo. c, Ebf2 + p neurons were segregated into two groups, simple (red) and complex (blue), using a $k$ means test in MATLAB (see Materials and Methods) using values in $\boldsymbol{f}-\boldsymbol{h} . \boldsymbol{d}$, Representative dendrogram of the $L 4 \mathrm{Ebf} 2+\mathrm{p}$ apical tuft shown in $\boldsymbol{a}$. $\boldsymbol{e}$, Fraction of neurons with dendrites of a given order " $n$ " (first order values, primary dendrites are excluded). $\boldsymbol{f}-\boldsymbol{h}$, Frequency distribution histograms for maximum branch order $(\boldsymbol{f})$, total length of the apical dendritic tuft $(\boldsymbol{g})$, and depth of first bifurcation from the pial surface $(\boldsymbol{h})$ for all reconstructed Ebf2 $+p$ neurons $(n=48)$. Insets show mean \pm SEM. 
a
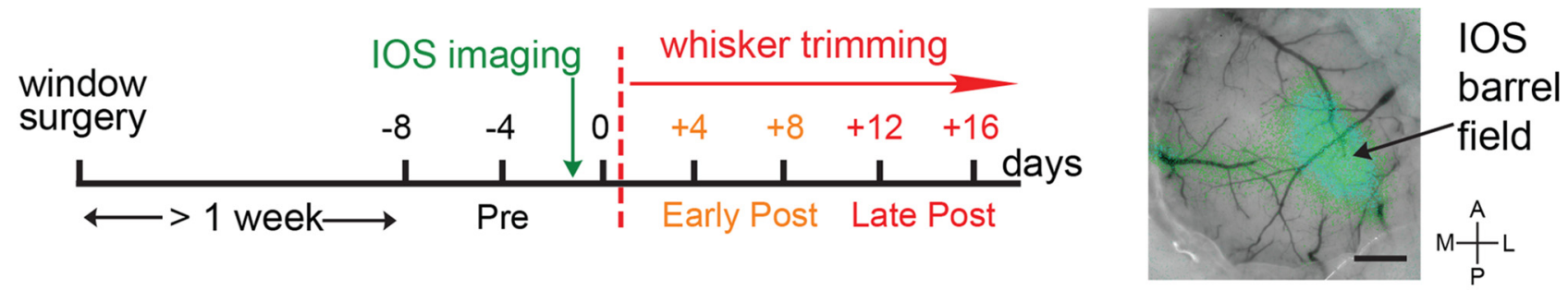

b
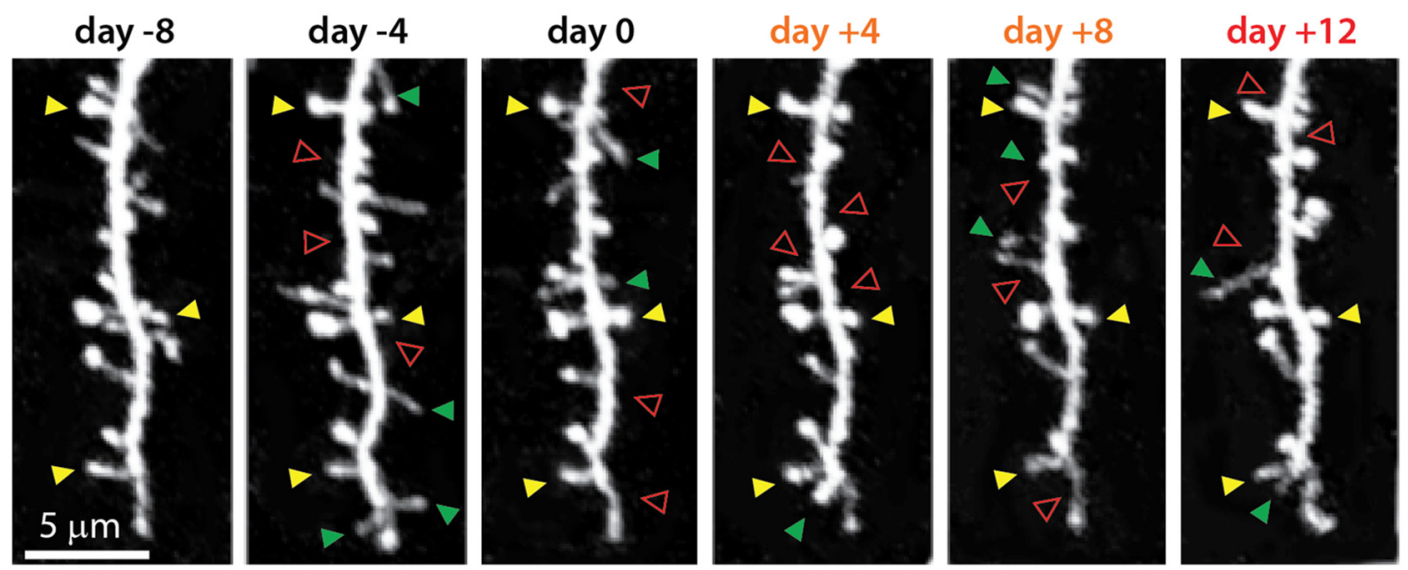

day +16
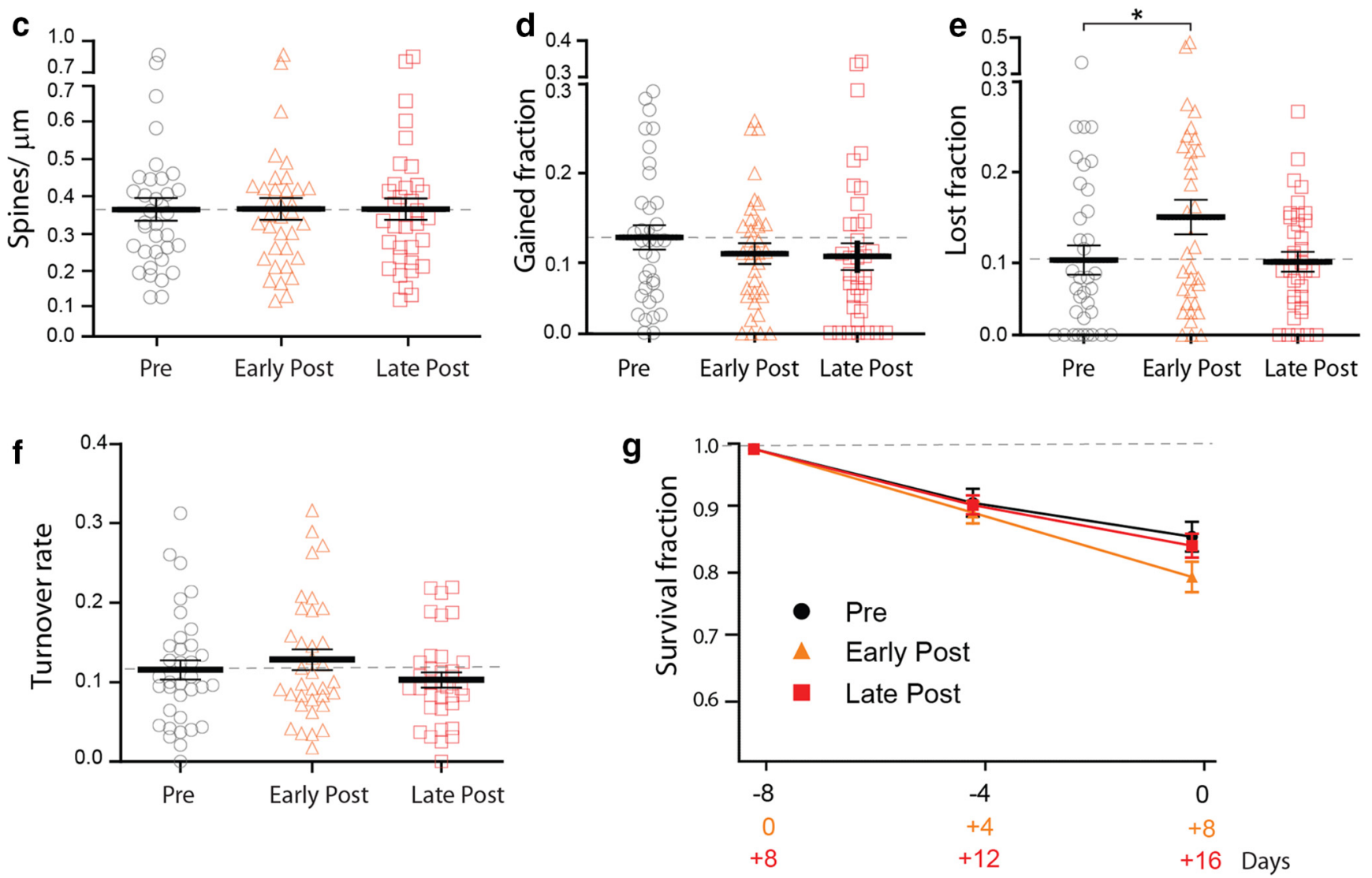

Figure 3. Spine dynamics and experience-dependent plasticity of Ebf2 $+L 4$ pyramidal neurons. $\boldsymbol{a}$, Experimental design (left) and representative IOS map of barrel cortex (right). Scale bar: $100 \mu \mathrm{m}$. A, Anterior; P, posterior; M, medial; L, lateral. $\boldsymbol{b}$, Example of longitudinal in vivo two-photon imaging of the same dendritic fragment before and after contralateral whisker trimming (pre or basal conditions: days $-8,-4$, and 0 , black; early-post: days +4 and +8 , orange; and late-post: days +12 and +16 , red) from an adult Ebf2-Cre;rAAV-EGFP mouse. Images are best projections of $\sim 5-7$ slices, $1 \mu \mathrm{m}$ apart. Yellow, green, and red arrowheads indicate examples of persistent, gained, and lost spines, respectively. $\mathbf{c}-\boldsymbol{f}$, Scatter plots of spine density $(\boldsymbol{c})$, spine turnover rate $(\boldsymbol{f})$, and fractions of gained $(\boldsymbol{d})$ and lost $(\boldsymbol{e})$ spines (mean $\pm \mathrm{SEM} ;{ }^{*} p<0.05$, linear mixed model). $\boldsymbol{g}$, Survival fraction of spines over 4 and $8 \mathrm{~d}$ (during the pre, early-post, and late-post time intervals). 


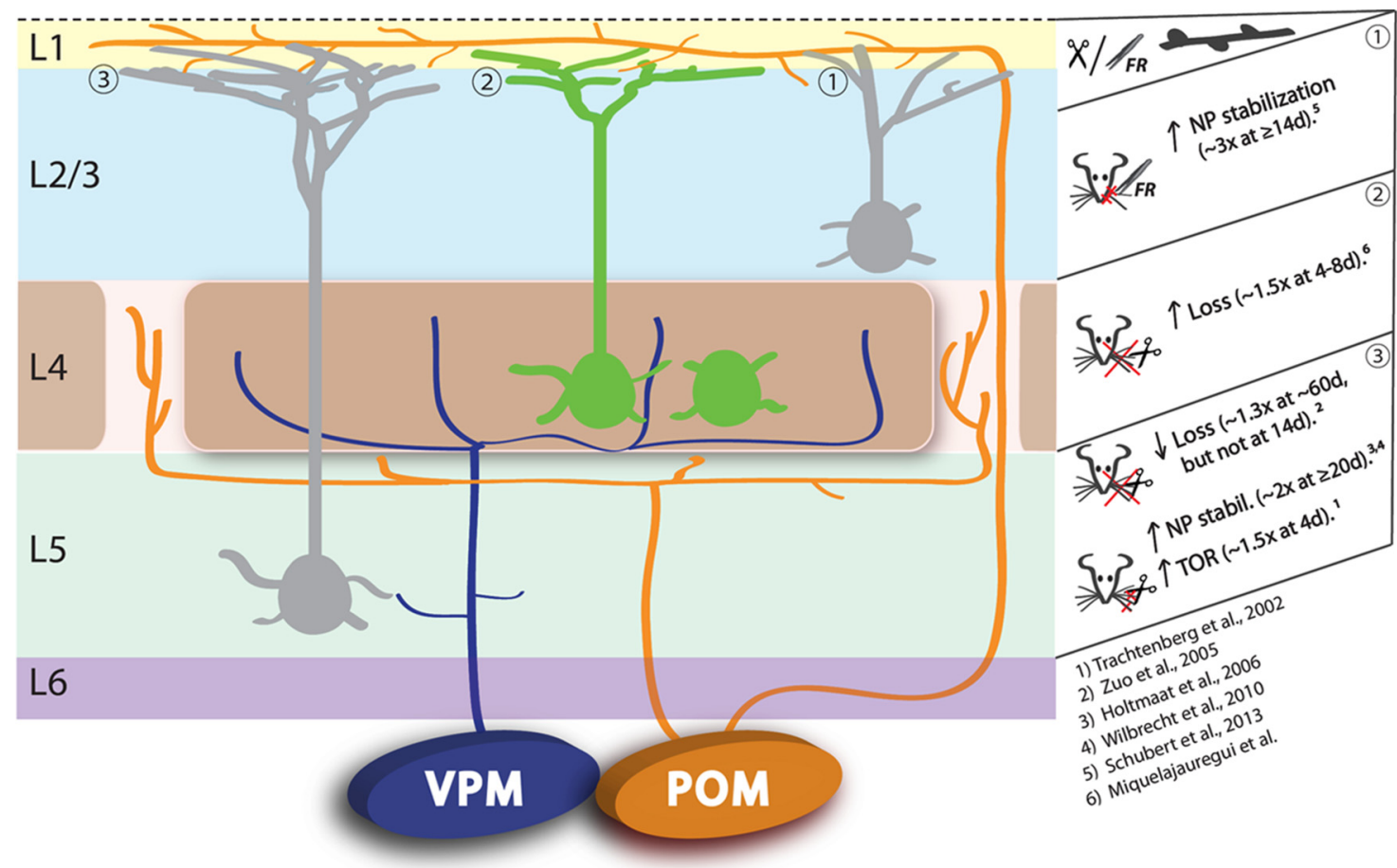

Figure 4. Experience-dependent spine plasticity in barrel cortex. Summary diagram of spine changes in apical tufts of neurons from different layers, documented by in vivo two-photon imaging studies. TOR, Turnover rate; FR, follicle removal.

branches per neuron was $9.75 \pm 0.89$; and the average maximum branch order was $4.2 \pm 0.2$ (Fig. $2 e-h$ ). We used a $k$ means cluster analysis to sort Ebf $2+\mathrm{p}$ neurons into simple and complex categories based on morphological characteristics (Fig. 2c); most ( $~ 94 \%)$ Ebf $2+$ p neurons were "simple" (possessing simple apical dendritic arbors), while a minority (3/48) had more complex apical dendritic arbors that bifurcated deeper below the pia and had cell bodies at depths $>500 \mu \mathrm{m}$ below the pia (data not shown).

\section{Experience-dependent plasticity of apical dendritic spines in L4 Ebf2+ pyramidal neurons in barrel cortex}

To investigate whether L4 Ebf $2+\mathrm{p}$ neurons exhibit dynamic changes in response to whisker input deprivation, we longitudinally imaged apical dendritic branches parallel to the pial surface in adult Ebf2-Cre;rAAV-EYFP mice. We confirmed that neurons we imaged were in barrel cortex with IOS imaging (Fig. $3 a$; see Materials and Methods). We chose a standard protocol for imaging spines every $4 \mathrm{~d}$ (Holtmaat et al., 2006; Mostany et al., 2010, 2013; Wilbrecht et al., 2010; Johnston et al., 2013; Kuhlman et al., 2014), which accounts well for the existence of populations of spines with different lifetimes (Mostany et al., 2013). Spine dynamics were analyzed before and after whisker trimming at two time-points: early-post $(4-8 \mathrm{~d})$ and late-post (12-16 d; Fig. $3 a, b)$.

After sensory input deprivation (unilateral trimming of all whiskers on the contralateral snout every $2 \mathrm{~d}$ ), the density of spines did not change significantly $(0.36 \pm 0.03$ spines $/ \mu \mathrm{m}$ at "pre" conditions vs $0.37 \pm 0.03$ spines $/ \mu \mathrm{m}$ at early-post, and $0.036 \pm 0.03$ spines $/ \mu \mathrm{m}$ at late-post; $p=0.99 ; n=35$ dendritic segments, 29 neurons, 9 mice; Fig. $3 c$ ). Similarly, the fraction of spines gained after each imaging session was not significantly altered $(p=0.50 ; 0.13 \pm 0.01$ pre vs $0.11 \pm 0.01$ early, and $0.11 \pm$ 0.02 spines $/ \mu \mathrm{m}$ late; Fig. $3 d)$. In contrast, the fraction of lost spines exhibited a significant $\sim 50 \%$ increase shortly after input deprivation $(0.10 \pm 0.02$ at basal pre vs $0.15 \pm 0.02$ at $4-8 \mathrm{~d}$ at early-post; $p=0.029$ pre vs early-post; Fig. $3 e$ ). The fraction of lost spines then returned to baseline levels 12-16 d after the onset of trimming $(0.10 \pm 0.01$ at late-post; $p=0.92$, pre vs late-post; Fig. $3 e$ ). We also analyzed the survival fraction of spines present at $-8,0$, and $+8 \mathrm{~d}$ that remains at two subsequent imaging sessions, and found no significant differences between groups (pre-trimming baseline: $0.86 \pm 0.02$; early-post trimming: $0.80 \pm 0.02$; late-post trimming: $0.86 \pm 0.02 ; p=0.11$, ANOVA; Fig. $3 g$ ). Despite the increase in spine loss, overall spine turnover rate (defined as the fraction of spines that appear and disappear over time) did not change significantly after whisker trimming $(0.12 \pm 0.01$ at pre vs $0.13 \pm 0.01$ at early-post and $0.10 \pm 0.01$ at late-post; $p=0.16$; Fig. $3 f$ ).

\section{Discussion}

Using chronic in vivo two-photon imaging at the barrel cortex, we investigated adult experience-dependent plasticity in dendritic spines of L4 pyramidal neurons, known recipients of thalamic innervation and ideal candidates for input integration due to the columnar and translaminar nature of their dendritic projections (Lübke et al., 2000; Staiger et al., 2004; Schoonover et al., 2014). We identified robust synaptic plasticity with a dramatic (50\%) increase in spine elimination immediately after whisker trimming, followed by a return to normal spine dynamics at 2 weeks of continuous whisker deprivation. To our knowledge, this is the first demonstration of experience-dependent changes in spine dynamics in L4 neurons in vivo. Thus, complete unilateral input deprivation leads to a loss of pre-existing spines in L4 pyramidal neurons in the contralateral cortex, presumably in response to loss of afferent sensory input. 
In the absence of compensatory changes in the fraction of spines gained (Fig. 3d), we might have expected to find a slight decrease in spine density (on the order of $0.02 / \mu \mathrm{m}$ ) but this was within our margin of error $( \pm 0.03 / \mu \mathrm{m})$ when estimating spine density (Fig. 3c). Notably, previous in vivo imaging studies of experience-dependent spine plasticity in L5B and L2/3 pyramidal neurons after input deprivation (Fig. 4) also found stable spine densities (Trachtenberg et al., 2002; Zuo et al., 2005b; Holtmaat et al., 2006; Wilbrecht et al., 2010; Schubert et al., 2013). The increased rate of spine elimination was transient and could not be detected after 2 weeks of continuous whisker trimming, which fits with prior observations in L5B, where whisker input deprivation led to delayed spine elimination $>2$ months (Zuo et al., 2005b), but not at 2 weeks after deprivation. Perhaps not surprisingly, spine plasticity in L4 neurons precedes that in L5B and correlates with the reduction of thalamocortical input density in L4 upon unilateral trimming ( $>3 \mathrm{~d}$; Oberlaender et al., 2012). Of course, differences in cell types (L4 vs L5B) and/or trimming paradigms (complete unilateral vs chessboard) may also account for differences in results between different studies, as previously argued (Chen et al., 2014).

This study was possible because we identified a BAC transgenic mouse line (Ebf2-Cre) that drives strong Cre expression in L4 excitatory neurons (both spiny stellates and pyramidal neurons). A subset of these L4 neurons demonstrated a pyramidal morphology (Fig. 2). Cluster analysis of quantified morphological parameters of apical dendrites from L4 pyramidal neuron revealed that Ebf2+ L4 pyramidal neurons are typically simpletufted and comparable to what others have referred to as "class 3 " narrow L5 pyramidal neurons in primary visual cortex (Tsiola et al., 2003). A small fraction (6\%) of Ebf $2+\mathrm{p}$ cells was similar to L5B complex pyramidal neurons labeled in Thyl mice (Holtmaat et al., 2006; Mostany et al., 2013).

Sensory processing in the barrel cortex involves the orchestrated activity of different cell types. Both L4 and infragranular layers receive parallel independent thalamic inputs (Constantinople and Bruno, 2013) and L4 neurons are readily activated in vivo by such inputs (Jia et al., 2014; Schoonover et al., 2014). Moreover, L4 (but not L5) neurons are affected by impairments in thalamocortical drive (Li et al., 2013). Whether the experiencedependent spine plasticity that we observed in $\mathrm{Eb} 2+$ p neurons is a direct consequence of thalamocortical input loss [presumably from posteromedial nucleus (POm); Meyer et al., 2010] or a correlate of more complex information processing in the cortex, will require further studies. What is clear is that, despite accounting for a smaller fraction of the total input to L4, POm synapses (paralemniscal pathway; Fig. 4) may be the main drivers of activity onto apical dendrites of L4 neurons (Feldmeyer et al., 2013; Pouchelon et al., 2014) and thus have a substantial impact on the circuit.

\section{References}

Chen CC, Lu J, Zuo Y (2014) Spatiotemporal dynamics of dendritic spines in the living brain. Front Neuroanat 8:28. CrossRef Medline

Chiara F, Badaloni A, Croci L, Yeh ML, Cariboni A, Hoerder-Suabedissen A, Consalez GG, Eickholt B, Shimogori T, Parnavelas JG, Rakić S (2012) Early B-cell factors 2 and 3 (EBF2/3) regulate early migration of CajalRetzius cells from the cortical hem. Dev Biol 365:277-289. CrossRef Medline

Constantinople CM, Bruno RM (2013) Deep cortical layers are activated directly by thalamus. Science 340:1591-1594. CrossRef Medline

Cruz-Martín A, Crespo M, Portera-Cailliau C (2010) Delayed stabilization of dendritic spines in fragile X mice. J Neurosci 30:7793-7803. CrossRef Medline

Feldmeyer D, Brecht M, Helmchen F, Petersen CC, Poulet JF, Staiger JF,
Luhmann HJ, Schwarz C (2013) Barrel cortex function. Prog Neurobiol 103:3-27. CrossRef Medline

Feng G, Mellor RH, Bernstein M, Keller-Peck C, Nguyen QT, Wallace M, Nerbonne JM, Lichtman JW, Sanes JR (2000) Imaging neuronal subsets in transgenic mice expressing multiple spectral variants of GFP. Neuron 28:41-51. CrossRef Medline

Holtmaat A, Svoboda K (2009) Experience-dependent structural synaptic plasticity in the mammalian brain. Nat Rev Neurosci 10:647-658. CrossRef Medline

Holtmaat AJ, Trachtenberg JT, Wilbrecht L, Shepherd GM, Zhang X, Knott GW, Svoboda K (2005) Transient and persistent dendritic spines in the neocortex in vivo. Neuron 45:279-291. CrossRef Medline

Holtmaat A, Wilbrecht L, Knott GW, Welker E, Svoboda K (2006) Experience-dependent and cell-type-specific spine growth in the neocortex. Nature 441:979-983. CrossRef Medline

Holtmaat A, Bonhoeffer T, Chow DK, Chuckowree J, De Paola V, Hofer SB, Hübener M, Keck T, Knott G, Lee WC, Mostany R, Mrsic-Flogel TD, Nedivi E, Portera-Cailliau C, Svoboda K, Trachtenberg JT, Wilbrecht L (2009) Long-term, high-resolution imaging in the mouse neocortex through a chronic cranial window. Nat Protoc 4:1128-1144. CrossRef Medline

Jia H, Varga Z, Sakmann B, Konnerth A (2014) Linear integration of spine $\mathrm{Ca} 2+$ signals in layer 4 cortical neurons in vivo. Proc Natl Acad Sci U S A 111:9277-9282. CrossRef Medline

Johnston DG, Denizet M, Mostany R, Portera-Cailliau C (2013) Chronic in vivo imaging shows no evidence of dendritic plasticity or functional remapping in the contralesional cortex after stroke. Cereb Cortex 23:751762. CrossRef Medline

Kuhlman SJ, O'Connor DH, Fox K, Svoboda K (2014) Structural plasticity within the barrel cortex during initial phases of whisker-dependent learning. J Neurosci 34:6078-6083. CrossRef Medline

Li H, Fertuzinhos S, Mohns E, Hnasko TS, Verhage M, Edwards R, Sestan N, Crair MC (2013) Laminar and columnar development of barrel cortex relies on thalamocortical neurotransmission. Neuron 79:970-986. CrossRef Medline

Lübke J, Egger V, Sakmann B, Feldmeyer D (2000) Columnar organization of dendrites and axons of single and synaptically coupled excitatory spiny neurons in layer 4 of the rat barrel cortex. J Neurosci 20:5300-5311. Medline

Meyer HS, Wimmer VC, Hemberger M, Bruno RM, de Kock CP, Frick A, Sakmann B, Helmstaedter M (2010) Cell type-specific thalamic innervation in a column of rat vibrissal cortex. Cereb Cortex 20:2287-2303. CrossRef Medline

Mostany R, Portera-Cailliau C (2008) A craniotomy surgery procedure for chronic brain imaging. J Vis Exp 12:e680. CrossRef Medline

Mostany R, Chowdhury TG, Johnston DG, Portonovo SA, Carmichael ST, Portera-Cailliau C (2010) Local hemodynamics dictate long-term dendritic plasticity in peri-infarct cortex. J Neurosci 30:14116-14126. CrossRef Medline

Mostany R, Anstey JE, Crump KL, Maco B, Knott G, Portera-Cailliau C (2013) Altered synaptic dynamics during normal brain aging. J Neurosci 33:4094-4104. CrossRef Medline

Oberlaender M, Ramirez A, Bruno RM (2012) Sensory experience restructures thalamocortical axons during adulthood. Neuron 74:648-655. CrossRef Medline

Pologruto TA, Sabatini BL, Svoboda K (2003) ScanImage: flexible software for operating laser scanning microscopes. Biomed Eng Online 2:13. CrossRef Medline

Pouchelon G, Gambino F, Bellone C, Telley L, Vitali I, Lüscher C, Holtmaat A, Jabaudon D (2014) Modality-specific thalamocortical inputs instruct the identity of postsynaptic L4 neurons. Nature 511:471-474. CrossRef Medline

Schoonover CE, Tapia JC, Schilling VC, Wimmer V, Blazeski R, Zhang W, Mason CA, Bruno RM (2014) Comparative strength and dendritic organization of thalamocortical and corticocortical synapses onto excitatory layer 4 neurons. J Neurosci 34:6746-6758. CrossRef Medline

Schubert V, Lebrecht D, Holtmaat A (2013) Peripheral deafferentationdriven functional somatosensory map shifts are associated with local, not large-scale dendritic structural plasticity. J Neurosci 33:9474-9487. CrossRef Medline

Staiger JF, Flagmeyer I, Schubert D, Zilles K, Kötter R, Luhmann HJ (2004) Functional diversity of layer IV spiny neurons in rat somato- 
sensory cortex: quantitative morphology of electrophysiologically characterized and biocytin labeled cells. Cereb Cortex 14:690-701. CrossRef Medline

Trachtenberg JT, Chen BE, Knott GW, Feng G, Sanes JR, Welker E, Svoboda $\mathrm{K}$ (2002) Long-term in vivo imaging of experience-dependent synaptic plasticity in adult cortex. Nature 420:788-794. CrossRef Medline

Tsiola A, Hamzei-Sichani F, Peterlin Z, Yuste R (2003) Quantitative morphologic classification of layer 5 neurons from mouse primary visual cortex. J Comp Neurol 461:415-428. CrossRef Medline

Wilbrecht L, Holtmaat A, Wright N, Fox K, Svoboda K (2010) Structural plasticity underlies experience-dependent functional plasticity of cortical circuits. J Neurosci 30:4927-4932. CrossRef Medline
Xu T, Yu X, Perlik AJ, Tobin WF, Zweig JA, Tennant K, Jones T, Zuo Y (2009) Rapid formation and selective stabilization of synapses for enduring motor memories. Nature 462:915-919. CrossRef Medline

Yang G, Lai CS, Cichon J, Ma L, Li W, Gan WB (2014) Sleep promotes branch-specific formation of dendritic spines after learning. Science 344: 1173-1178. CrossRef Medline

Zuo Y, Lin A, Chang P, Gan WB (2005a) Development of long-term dendritic spine stability in diverse regions of cerebral cortex. Neuron 46:181189. CrossRef Medline

Zuo Y, Yang G, Kwon E, Gan WB (2005b) Long-term sensory deprivation prevents dendritic spine loss in primary somatosensory cortex. Nature 436:261-265. CrossRef Medline 